\title{
Impact of Diabetes Mellitus on the Outcomes After Pancreaticoduodenectomy for Pancreatic Ductal Adenocarcinoma: A Single Center Experience
}

\author{
Ayman El Nakeeb, Ahmed Shehta, Rami Said, Mohamed El Dosoky, Ahmed Moneer, \\ Mohamed Elrefai, Hosam Hamed, Talaat Abd Allah
}

Corresponding author:

Ayman El Nakeeb, MD

Professor of general surgery, hepatobiliary and pancreatic surgery Gastroenterology Surgical Center

Mansoura University, Egypt

E-mail: elnakeebayman@yahoo.com

Received: 01.02.2018

Accepted: 10.03 .2018

Copyright () Celsius Publishing House www.sgo-iasgo.com
Gastroenterology Surgical Center, Mansoura University, Egypt

\section{ABSTRACT}

Purpose: Pancreatic ductal adenocarcinoma is a life-threatening health problem. Surgical excision is the principal step of multimodal treatment, but it is associated with poor outcomes. At the time of diagnosis, up to $80 \%$ of those patients have impaired glucose tolerance or diabetes mellitus. The role of pre-operative diabetes mellitus on the outcomes after pancreaticoduodenectomy is still unclear.

Method: We reviewed the data of patients who underwent pancreaticoduodenectomy for pancreatic ductal adenocarcinoma. Patients were divided into 2 groups according to presence or absence of preoperative diabetes mellitus.

Results: Our study included 451 patients. Diabetes mellitus group included 113 patients (25.1\%), and non-diabetes mellitus group included 338 patients (74.9\%). More firm pancreas was found in diabetes mellitus group, and more clinically relevant postoperative pancreatic fistula was found in non-diabetes mellitus group. There was more delayed gastric emptying, and wound infection in diabetes mellitus group. The long-term outcomes were comparable between groups regarding the overall $(p=0.55)$ and disease-free survival rates $(p=0.972)$.

Conclusion: Preoperative diabetes mellitus did not affect the perioperative outcomes after pancreaticoduodenectomy for pancreatic ductal adenocarcinoma. Preoperative diabetes mellitus is not associated with postoperative pancreatic fistula; however, it is significantly associated with delayed gastric emptying and wound infection.

Key words: diabetes mellitus, pancreaticoduodenectomy, pancreaticogastrostomy, pancreaticojejunostomy, pancreatic fistula

\section{INTRODUCTION}

Pancreatic ductal adenocarcinoma (PDAC) is a life-threatening health problem/condition that poses substantial challenges in its management. It is the $10^{\text {th }}$ most common cancer worldwide, and the 4th main cause of cancer-related death (1). 
Although many patients have an unresectable disease at the time of diagnosis, radical surgical excision is the principal step of multimodal treatment to achieve adequate long-term outcomes (2).

Post-operative morbidity after pancreatic resection still high with poor survival outcomes even with advancement in perioperative care $(3,4)$.

Several risk factors have been identified to be associated with the development of post-operative morbidity and poor long term outcomes, but the role of pre-operative diabetic status in this setting is still unclear. At the time of diagnosis, up to $80 \%$ of PDAC cases have either impaired glucose tolerance or clinically manifest diabetes mellitus (DM) $(5,6)$. On the other hand, it is unclear whether preoperative DM is a predisposing factor or a possible consequence of PDAC, or both.

Few studies have evaluated the impact of preoperative DM on perioperative and long term outcomes after pancreatic resection for PDAC. The results of these studies are very controversial, and most of them included tumors that are located in all parts of the pancreas (7-10). We aimed to evaluate the impact of preoperative DM on the perioperative and long term outcomes of patients who underwent pancreaticoduodenenctomy (PD) for pancreatic ductal adenocarcinoma of the pancreatic head in a tertiary high volume center.

\section{PATIENTS AND METHODS}

\section{Study Design}

We retrospectively reviewed the data of all patients who underwent PD for periampullary tumors at Gastroenterology Surgical Center, Mansoura University, Egypt during the period between January 1993 and December 2016. Patient data were reviewed from a prospectively maintained database for all patients undergoing PD since 2000 and before 2000, the data were reviewed from the archive files of the patients. A written informed consent for the surgical procedures was obtained from each patient.

Patients with pathologically confirmed PDAC were only included in this study, while other periampullary tumors were excluded. Patients were divided into two groups according to the presence or absence of preoperative DM. Faculty of Medicine, Mansoura University review board approved this study.

\section{Preoperative assessment}

Preoperative assessment included clinical, laboratory and radiological evaluation as described in previous studies $(11,12)$.

\section{Surgical procedures}

The surgical technique including dissection and reconstructions is described in previous studies $(12,13)$.

\section{Postoperative care and follow up}

Post-operatively, all patients received intra-venous antibiotics and proton pump inhibitors. Somatostatin analogues were administered in some selected cases (100 $\mu \mathrm{g}$ subcutaneously every 8 hours). Clinical and radiological follow up were performed postoperatively.

In patients with smooth post-operative course oral intake was resumed on the 4 th post-operative day then oral solid food afterwards.

After discharge, patients were followed up after 1 week in outpatient clinic. They were scheduled for routine follow up visits at 1, 3, 6 month after surgery, then every 6 month. Follow up visits included complete clinical evaluation, laboratory evaluation including tumor markers (CA 19-9), and radiological evaluation (abdominal ultrasonography and/or triphasic computed tomography).

\section{Clinical outcomes}

Diagnosis of DM was made according to clinical history and past laboratory tests based on the 2010 American Diabetes Association criteria (14). Patients with a known history of DM, a preoperative fasting blood glucose level $\geq 126 \mathrm{mg} / \mathrm{dL}$, or two or more outpatient random blood glucose levels $\geq 200 \mathrm{mg} / \mathrm{dL}$ were included into the DM group. For patients with only inpatient preoperative laboratory results, those with two or more serum measurements $\geq 200 \mathrm{mg} / \mathrm{dL}$ obtained before 7:00 AM were also included into the DM group. Only laboratory analyzed blood samples were considered. Blood glucose measurements by routine glucose meters were not considered.

Postoperative morbidity was defined and graded according to the Clavien-Dindo classification (15).

Post-operative pancreatic fistula (POPF), delayed gastric emptying (DGE), biliary leakage were defined according to the International Study Group for Pancreatic Fistula (ISGPF) (16-18). 
Postoperative mortality was defined as death within 90 days after liver resection.

Overall survival (OS) is calculated from the day of surgery to the day of death or last follow up.

Disease free survival (DFS) is calculated from the day of surgery to the day of tumor recurrence or the day of death or last follow up.

\section{Outcomes of the study}

The primary outcome was the rate of POPF.

Secondary outcomes included length of postoperative stay, time to resume oral intake, total postoperative morbidity according to Clavien-Dindo classification, delayed gastric emptying, biliary leakage, wound infection, hospital mortality, and survival outcomes (OS and DFS).

\section{Statistical analysis}

Statistical analysis of the data is performed using SPSS software version 20. For continuous variables are reported as median and compared by independent sample t-test or Mann-Whitney for continuous variables when appropriate. Categorical variables are described using frequency distributions and compared by Chi-square test. Survival rates were calculated by Kaplan-Meier method and were compared by log rank test. A p values $<0.05$ is considered to be significant.

\section{RESULTS}

During the study period, 980 patients underwent PD for periampullary tumors at our center. Of them 451 patients had pathologically confirmed PDAC and were only included in this study, while other periampullary tumors were excluded. Patients were divided into two groups according to the presence or absence of preoperative DM. DM group included 113 patients (25.1\%), and Non-DM group included 338 patients (74.9\%).

\section{Baseline characteristics}

Baseline characteristics of the patients are shown in table 1. There were significant differences between the two groups regarding preoperative fever, and abdominal pain, and random blood glucose.

\section{Surgical outcomes}

Operative data of the patients are also shown in table 1. There was more firm pancreas in DM group, and this was statistically significant.

The postoperative data of the patients are shown in table 2. There was more clinically relevant POPF in NonDM group. There were more DGE, especially grade $C$, in DM group which required longer nasogastric tube decompression. Also, there were more wound infection rate in DM group.

The median follow up period for all patients was 24 month (4-120 month). The OS and DFS curves of all patients are shown in figs. $1 a, 1 b$.

Recurrence occurred in 53 patients $(11.8 \%), 10$ patients (8.8\%) in DM group and 43 patients (12.7\%) in Non-DM group, with no statistically significant difference between the groups $(p=0.269)$.

Mortality occurred in 306 patients (67.8\%), 56 patients (49.6\%) in DM group and 250 patients (74\%) in Non-DM group, and this was statistically significant $(p<$ 0.001).

The long-term oncological outcomes were comparable between groups regarding the OS rates ( $p=0.55)$ and DFS $(p=0.972)$. The 1-, 3-, and 5- year OS rates were $80.4 \%, 35.5 \%$, and $0 \%$, respectively, in DM group, and $83.2 \%, 35.2 \%$, and $7.3 \%$, respectively, in Non-DM group (fig. 1c). The 1-, 3-, and 5-year DFS rates were $70 \%, 0 \%$, and $0 \%$, respectively, in the DM group, and $53.5 \%, 4.7 \%$, and $0 \%$, respectively, in Non-DM group (fig. 1d).

\section{Predictors of POPF}

On univariate analysis, significant factors associated with POPF included preoperative loss of weight, preoperative body mass index [weight $(\mathrm{kg}) /$ height $\left(\mathrm{m}^{2}\right)$ ], presence of soft pancreas, and pancreatic stent as shown in table 3.

On multivariate analysis, significant factors associated with POPF included preoperative loss of weight, presence of soft pancreas, and pancreatic stent as shown in table 3.

\section{DISCUSSION}

DM and poor glycemic control have been shown to be significant predictors for adverse postoperative and long term outcomes after different surgical operations, including digestive tract operations (19-21).

The association between DM and PDAC is demonstrated by previous studies $(6,22-24)$. At the time of diagnosis of PDAC, about $20-65 \%$ of patients have coexisting DM, and up to $80 \%$ of patients have impaired glucose tolerance exceeding the disease prevalence in 
Table 1 - Baseline characteristics of the study patients

\begin{tabular}{|c|c|c|c|c|}
\hline Variables & $\begin{array}{l}\text { All } \\
451\end{array}$ & $\begin{array}{c}\text { DM } \\
113(25.1 \%)\end{array}$ & $\begin{array}{c}\text { Non-DM } \\
338(74.9 \%)\end{array}$ & $P$ value \\
\hline Age (years) & $55(12-88)$ & $55(12-88)$ & $55(25-79)$ & 0.186 \\
\hline $\begin{array}{l}\text { Sex } \\
\text { Male } \\
\text { Female }\end{array}$ & $\begin{array}{l}291(64.5 \%) \\
160(35.5 \%)\end{array}$ & $\begin{array}{l}72(63.7 \%) \\
41(36.3 \%)\end{array}$ & $\begin{array}{l}219(64.8 \%) \\
119(35.2 \%)\end{array}$ & 0.836 \\
\hline $\begin{array}{l}\text { BMI }\left(\mathrm{kg} / \mathrm{m}^{2}\right) \\
\text { Less than } 25 \\
\text { More than } 25\end{array}$ & $\begin{array}{l}323(71.6 \%) \\
128(28.4 \%)\end{array}$ & $\begin{array}{l}74(65.5 \%) \\
39(34.5 \%)\end{array}$ & $\begin{array}{c}249(73.7 \%) \\
89(26.3 \%)\end{array}$ & 0.095 \\
\hline $\begin{array}{l}\text { Presentation } \\
\text { Jaundice } \\
\text { Fever } \\
\text { Abdominal pain } \\
\text { Vomiting }\end{array}$ & $\begin{array}{c}428(94.9 \%) \\
103(22.8 \%) \\
337(74.4 \%) \\
48(10.6 \%)\end{array}$ & $\begin{array}{l}110(97.3 \%) \\
18(15.9 \%) \\
74(65.5 \%) \\
16(14.2 \%)\end{array}$ & $\begin{array}{c}318(94.1 \%) \\
85(25.1 \%) \\
263(77.8 \%) \\
32(9.5 \%)\end{array}$ & $\begin{array}{l}0.173 \\
0.044 \\
0.009 \\
0.162\end{array}$ \\
\hline $\begin{array}{l}\text { Preoperative labs } \\
\text { Albumin }(\mathrm{g} / \mathrm{dl}) \\
\text { Bilirubin }(\mathrm{mg} / \mathrm{dl}) \\
\text { Blood glucose }(\mathrm{mg} / \mathrm{dl})\end{array}$ & $\begin{array}{c}4(2.4-5.8) \\
5.5(0.4-38) \\
110(70-520)\end{array}$ & $\begin{array}{c}4(3-5.8) \\
5.5(0.4-36) \\
165(70-520)\end{array}$ & $\begin{array}{l}4(2.4-5.1) \\
5.5(0.5-38) \\
95(72-140)\end{array}$ & $\begin{array}{l}0.939 \\
0.754 \\
0.000\end{array}$ \\
\hline Preoperative ERCP & $224(49.7 \%)$ & $60(53.1 \%)$ & $164(48.5 \%)$ & 0.4 \\
\hline $\begin{array}{l}\text { Liver } \\
\text { Normal } \\
\text { Cirrhotic }\end{array}$ & $\begin{array}{c}398(88.2 \%) \\
53(11.8 \%)\end{array}$ & $\begin{array}{c}103(91.2 \%) \\
10(8.8 \%)\end{array}$ & $\begin{array}{c}295(87.3 \%) \\
43(12.7 \%)\end{array}$ & 0.235 \\
\hline $\begin{array}{l}\text { Pancreatic texture } \\
\text { Soft } \\
\text { Firm }\end{array}$ & $\begin{array}{l}258(57.2 \%) \\
193(42.8 \%)\end{array}$ & $\begin{array}{l}49(43.4 \%) \\
64(56.6 \%)\end{array}$ & $\begin{array}{l}209(61.8 \%) \\
129(38.2 \%)\end{array}$ & 0.001 \\
\hline PD diameter (mm) & $5(1-15)$ & $5(1-12)$ & $5(1-15)$ & 0.157 \\
\hline $\begin{array}{l}\text { PD diameter groups } \\
\text { Less than } 3 \mathrm{~mm} \\
\text { More than } 3 \mathrm{~mm}\end{array}$ & $\begin{array}{l}121(26.8 \%) \\
330(73.2 \%)\end{array}$ & $\begin{array}{l}28(24.8 \%) \\
85(75.2 \%)\end{array}$ & $\begin{array}{c}93(27.5 \%) \\
245(72.5 \%)\end{array}$ & 0.57 \\
\hline Operation time (hours) & $5(3.5-10)$ & $5(3.5-10)$ & $5(3.5-9)$ & 0.2 \\
\hline Blood loss (ml) & $500(50-3000)$ & $400(100-3000)$ & $500(50-3000)$ & 0.847 \\
\hline $\begin{array}{l}\text { Blood transfusion } \\
\text { No } \\
\text { Yes }\end{array}$ & $\begin{array}{l}201(44.6 \%) \\
250(55.4 \%)\end{array}$ & $\begin{array}{l}55(48.7 \%) \\
58(51.3 \%)\end{array}$ & $\begin{array}{l}146(43.2 \%) \\
192(56.8 \%)\end{array}$ & 0.114 \\
\hline
\end{tabular}

the general population $(5,6)$. It remains unclear whether preoperative DM is a predisposing factor or a consequence of PDAC development, or both. In the current study, the overall incidence of DM among PDAC patients was $25.1 \%$.

The impact of preoperative DM on the perioperative and long term outcome of after pancreatic resections, especially PD, for PDAC patients is of great importance. Few previous studies had evaluated the impact of preoperative DM on the outcomes of pancreatic resections for $\operatorname{PDAC}(9,10,25,26)$. The outcomes of such studies had been controversial, and many of these studies included all types of pancreatic resections.

POPF is the commonest and most feared major morbidity after PD. It is associated with longer hospitalization, abdominal collections, and sepsis. Also, it can lead to life-threatening events, such as secondary hemorrhage, multi-organ failure, and mortality (27). Previous studies tried to identify different predictive factors for POPF after PD. They identified several preoperative factors as old age, unintended weight loss, and malnutrition, and operative factors as soft pancreas, excess parenchymal fat, small pancreatic duct, longer operation time as predictive factors for POPF formation (28-30).

The impact of preoperative DM on POPF had been controversial between different studies. Chu et al found a significant higher POPF rate in DM patients than nonDM patients. They also found that preoperative DM was an independent predictor of increased POPF rate, but it did not significantly compromise the postoperative outcomes (7). Malleo et al found that preoperative 
Table 2 - Postoperative outcomes of the study patients

\begin{tabular}{|c|c|c|c|c|}
\hline Variables & $\begin{array}{l}\text { All } \\
451\end{array}$ & $\begin{array}{c}\text { DM } \\
113(25.1 \%)\end{array}$ & $\begin{array}{c}\text { Non-DM } \\
338(74.9 \%)\end{array}$ & $P$ value \\
\hline Hospital stay & $8(5-71)$ & $9(1-51)$ & $8(5-71)$ & 0.599 \\
\hline Start oral intake & $5(3-51)$ & $5(3-51)$ & $5(3-40)$ & 0.966 \\
\hline Drain removal & $8(4-71)$ & $9(4-51)$ & $8(4-71)$ & 0.933 \\
\hline Somatostatin use & $316(70.1 \%)$ & $77(68.1 \%)$ & $239(70.7 \%)$ & 0.24 \\
\hline $\begin{array}{l}\text { Complications } \\
\text { Overall } \\
1 \\
2 \\
3 \\
4 \\
5\end{array}$ & $\begin{array}{c}142(31.5 \%) \\
47(10.4 \%) \\
44(9.8 \%) \\
33(7.3 \%) \\
0 \\
18(4 \%)\end{array}$ & $\begin{array}{c}39(34.5 \%) \\
14(12.4 \%) \\
12(10.6 \%) \\
6(5.3 \%) \\
0 \\
7(6.2 \%)\end{array}$ & $\begin{array}{c}103(30.5 \%) \\
33(9.8 \%) \\
32(9.5 \%) \\
27(8 \%) \\
0(\%) \\
11(3.3 \%)\end{array}$ & $\begin{array}{l}0.424 \\
0.456\end{array}$ \\
\hline $\begin{array}{l}\text { Pancreatic fistula } \\
\text { Any } \\
\text { A } \\
\text { B } \\
\text { C } \\
\text { Clinically relevant pancreatic fistula }\end{array}$ & $\begin{array}{c}70(15.5 \%) \\
28(6.2 \%) \\
24(5.3 \%) \\
18(4 \%) \\
42(9.3 \%)\end{array}$ & $\begin{array}{c}13(11.5 \%) \\
8(7.1 \%) \\
2(1.8 \%) \\
3(2.7 \%) \\
5(4.5 \%)\end{array}$ & $\begin{array}{l}57(16.9 \%) \\
29(5.9 \%) \\
22(6.5 \%) \\
15(4.4 \%) \\
37(10.9 \%)\end{array}$ & $\begin{array}{l}0.174 \\
0.212\end{array}$ \\
\hline Biliary leakage & $35(7.8 \%)$ & $12(10.6 \%)$ & $23(6.8 \%)$ & 0.193 \\
\hline $\begin{array}{l}\text { Delayed gastric emptying } \\
\text { Any } \\
\text { A } \\
\text { B } \\
\text { C }\end{array}$ & $\begin{array}{c}77(17.1 \%) \\
22(4.9 \%) \\
47(10.4 \%) \\
8(1.8 \%)\end{array}$ & $\begin{array}{c}23(20.4 \%) \\
9(8 \%) \\
9(8 \%) \\
5(4.4 \%)\end{array}$ & $\begin{array}{c}54(16 \%) \\
13(3.8 \%) \\
38(11.2 \%) \\
3(0.9 \%)\end{array}$ & $\begin{array}{l}0.02 \\
0.03\end{array}$ \\
\hline $\begin{array}{l}\text { Types: } \\
\text { Primary } \\
\text { Secondary }\end{array}$ & $\begin{array}{c}13(2.9 \%) \\
64(14.2 \%)\end{array}$ & $\begin{array}{c}7(6.2 \%) \\
16(14.2 \%)\end{array}$ & $\begin{array}{c}6(1.8 \%) \\
48(14.2 \%)\end{array}$ & 0.07 \\
\hline Pancreatitis & $7(1.6 \%)$ & $3(2.7 \%)$ & $4(1.2 \%)$ & 0.274 \\
\hline Bleeding PG & $6(1.3 \%)$ & 0 & $6(1.8 \%)$ & 0.154 \\
\hline Bleeding GJ & $13(2.9 \%)$ & $2(1.8 \%)$ & $11(3.3 \%)$ & 0.415 \\
\hline GJ leakage & $5(1.1 \%)$ & $3(2.7 \%)$ & $2(0.6 \%)$ & 0.07 \\
\hline Obstructed GJ & $11(2.4 \%)$ & $1(0.9 \%)$ & $10(3 \%)$ & 0.215 \\
\hline Wound infection & $27(6 \%)$ & $15(13.3 \%)$ & $12(3.6 \%)$ & 0.000 \\
\hline Respiratory complications & $20(4.4 \%)$ & $4(3.5 \%)$ & $16(4.7 \%)$ & 0.594 \\
\hline Re-exploration & $32(7.1 \%)$ & $8(7.1 \%)$ & $24(7.1 \%)$ & 0.994 \\
\hline Perioperative mortality & $17(3.8 \%)$ & $6(5.3 \%)$ & $11(3.3 \%)$ & 0.321 \\
\hline $\begin{array}{l}\text { Disease-free survival } \\
1 \text { year } \\
3 \text { year } \\
5 \text { year }\end{array}$ & $\begin{array}{c}56.6 \% \\
5.7 \% \\
0\end{array}$ & $\begin{array}{c}70 \% \\
0 \\
0\end{array}$ & $\begin{array}{c}53.5 \% \\
4.7 \% \\
0\end{array}$ & Log-Rank 0.972 \\
\hline $\begin{array}{l}\text { Overall survival } \\
1 \text { year } \\
3 \text { year } \\
5 \text { year }\end{array}$ & $\begin{array}{l}82.5 \% \\
35 \% \\
7.2 \%\end{array}$ & $\begin{array}{c}80.4 \% \\
35.5 \% \\
0 \%\end{array}$ & $\begin{array}{c}83.2 \% \\
35.2 \% \\
7.3 \%\end{array}$ & Log-Rank 0.55 \\
\hline
\end{tabular}

DM is not a predictive factor for POPF after resection of PDAC. They also found that all grade "C" POPFs occurred only in non-DM patients (8).

In our study, POPF rate was higher in Non-DM group (57 patients - 16.9\%) than DM group (13 patients $11.5 \%$ ), and this was statistically non-significant ( $p=$
0.174). Clinically relevant POPF was significantly higher in Non-DM group (Non-DM: 37 (10.9\%), DM: 5 (4.5\%), $p$ value $=0.018)$. When we analyzed the predictive factors of POPF, preoperative DM was not a significant predictor of POPF ( $p=0.176)$. This can be attributed to significant higher incidence of firm pancreatic 
a

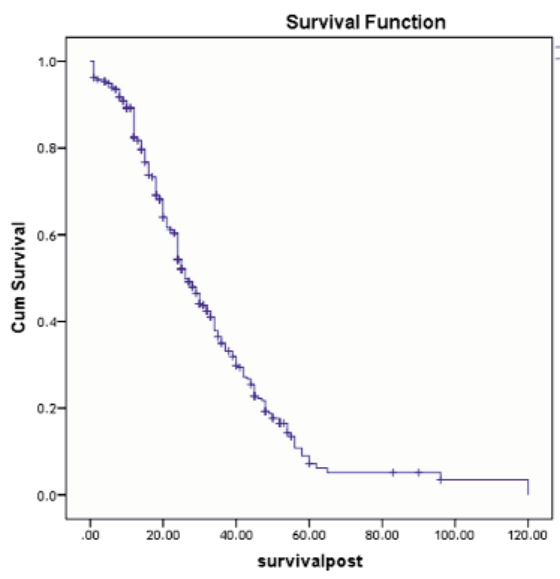

c

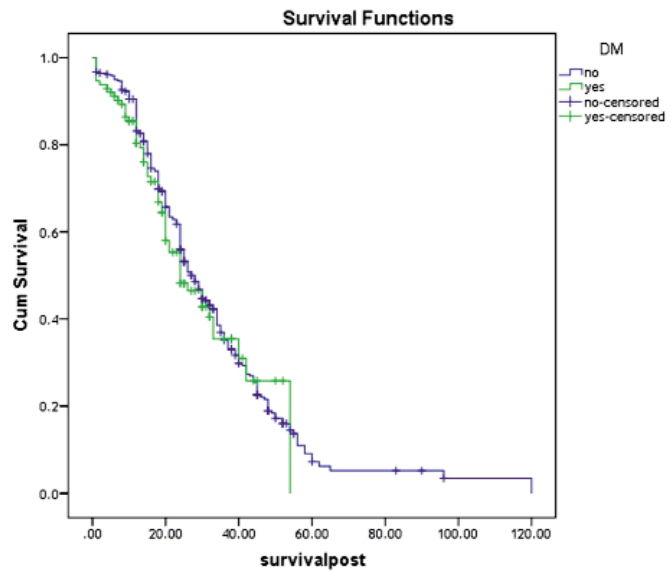

b

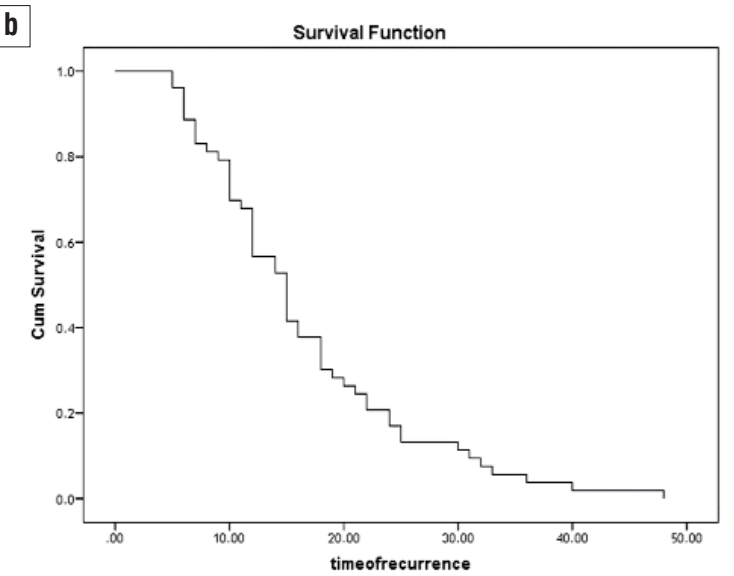

d

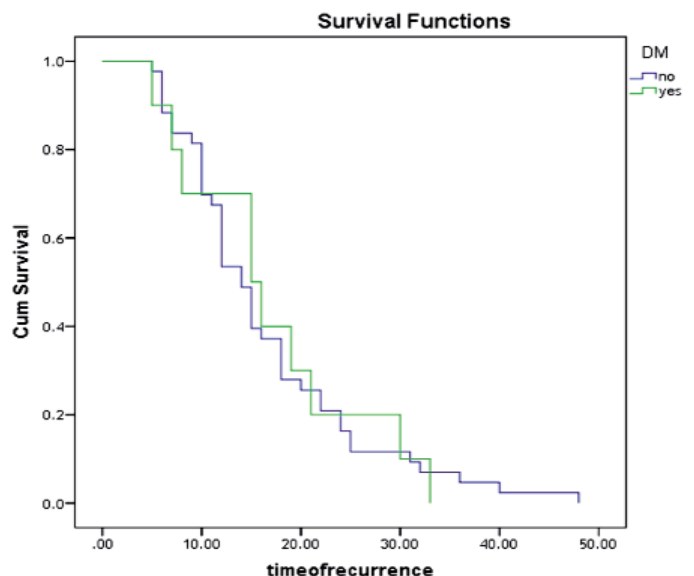

Figure 1 - (a) Overall survival of all study patients. (b) Disease-free survival of all study patients. (c) Overall survival rates of DM and Non-DM groups $(p=0.55$, Log-Rank test). (d) Disease-free survival rates of DM and Non-DM groups $(p=0.972$, Log-Rank test)

Table 3 - Univariate and multivariate analysis of predictors of postoperative pancreatic fistula

\begin{tabular}{|c|c|c|}
\hline & Univariate & Multivariate \\
\hline Age & 0.266 & \\
\hline Sex & 0.556 & \\
\hline Diabetes Mellitus & 0.176 & \\
\hline Body mass index & 0.03 & 0.07 \\
\hline Carbohydrate antigen $19-9$ & 0.429 & \\
\hline Preoperative hemoglobin & 0.427 & \\
\hline Preoperative WBCs & 0.558 & \\
\hline Preoperative albumin & 0.119 & \\
\hline Preoperative creatinine & 0.475 & \\
\hline Preoperative amylase & 0.187 & \\
\hline Preoperative ERCP & 0.646 & \\
\hline Liver cirrhosis & 0.181 & \\
\hline Mass size & 0.721 & \\
\hline Soft pancreas & 0.006 & 0.03 \\
\hline Mobilized part of pancreatic stump & 0.754 & \\
\hline Pancreatic duct diameter & 0.819 & \\
\hline Pancreatic duct to posterior border & 0.508 & \\
\hline Blood loss & 0.644 & \\
\hline Blood transfusion & 0.813 & \\
\hline Operation time & 0.577 & \\
\hline Somatostatin use & 0.963 & \\
\hline
\end{tabular}

parenchyma in DM group (64 patients $-56.6 \%$ ) than Non-DM (129 patients $-38.2 \%), p=0.001$. This association had been addressed by previous studies which found that DM patients had less pancreatic parenchymal fat and increased pancreatic parenchymal fibrosis $(8,29)$. This is addressed as higher degree "intrinsic gland fibrosis" by Malleo et al (8).

DGE is one of the most annoying morbidities after PD, with overall reported incidence of $13 \%$ to $42 \%$ (2830). The underlying pathophysiologic mechanism of DGE is still unclear. Previous studies had identified several underlying mechanisms such as lack of duodenal hormones, oedema of duodenojejunostomy, local ischaemia of the antrum, and gastric atony due to vagotomy (1-5).

On the other hand, DM is the most common cause of gastroparesis, related to vagal neuropathy, and hyperglycemia induced reduction of gastric emptying time (27). So, DM patients are expected to have a higher rate of DGE after PD.

Previous studies demonstrated that there was no association between preoperative DM and DGE rate 
after PD $(18,19)$.

In our study, we found significantly higher DGE rates in DM group (23 patients $-20.4 \%$ ) than Non-DM group (54 patients $-16 \%),(p=0.02)$. This required prolonged use of nasogastric tube in DM group than Non-DM group, and this was also statistically significant $(p=$ 0.005 ). We also found that significantly higher wound infection rate in DM group (15 patients - 13.3\%) than Non-DM group (12 patients $-3.6 \%)$, $(p<0.001)$.

Regarding the long-term outcomes, the outcomes of previous studies were heterogenous. Canon et al found that preoperative DM was a significant predictor of OS and DFS after pancreatic resection (10). Similar findings had been addressed by Cahgpar et al (9). In our study, there was statistically significant difference between DM and Non-DM groups regarding OS and DFS (Log-Rank: 0.55 and 0.972 respectively).

Limitations of this study includes that it is retrospective study over a long duration. The diagnosis of preoperative DM was made based on documented past history and laboratory glucose levels. It was not possible to differentiate between type I and type II DM. Hemoglobin A1c evaluation was not routinely done and so not available for all patients.

\section{CONCLUSIONS}

In conclusion, we found that preoperative DM did not significantly affect the perioperative outcomes after PD for PDAC patients, however, certain morbidities are affected by preoperative DM. Preoperative DM is not associated with POPF, and higher incidence of clinically relevant POPF occurred in non-diabetics. Preoperative DM was significantly associated with higher incidence of DGE and wound infection. Finally, preoperative DM did not compromise the OS and DFS rates.

\section{Conflict of interest}

No conflict of interest for any author.

\section{Author contributions}

Substantial contributions to the conception or design of the work; or the acquisition, analysis, or interpretation of data for the work; by Ayman El Nakeeb, Ahmed Shehta, Rami Said, Mohamed El Dosoky, Ahmed Moneer, Hosam Hamed, Mohamed Elrefai, Talaat Abd Allah. Drafting the work or revising it critically for important intellectual content; by Ayman El Nakeeb,
Ahmed Shehta. Final approval of the version to be published; by Ayman El Nakeeb, Ahmed Shehta. Agreement to be accountable for all aspects of the work in ensuring that questions related to the accuracy or integrity of any part of the work are appropriately investigated and resolved by Ayman El Nakeeb, Ahmed Shehta.

\section{REFERENCES}

1. Jemal A, Siegel R, Xu J, Ward E.. Cancer statistics, 2010. CA: a cancer journal for clinicians. CA Cancer J Clin. 2010;60(5):277-300.

2. Hartwig W, Hackert T, Hinz U, Gluth A, Bergmann F, Strobel O, et al. Pancreatic cancer surgery in the new millennium: better prediction of outcome. Ann Surg. 2011;254(2):311-9.

3. Vin Y, Sima CS, Getrajdman GI, Brown KT, Covey A, Brennan MF, et al. Management and outcomes of postpancreatectomy fistula, leak, and abscess: results of 908 patients resected at a single institution between 2000 and 2005. J Am Coll Surg. 2008;207(4):490-8.

4. Kooby DA, Gillespie T, Bentrem D, Nakeeb A, Schmidt MC, Merchant NB, et al. Left-sided pancreatectomy: a multicenter comparison of laparoscopic and open approaches. Ann Surg. 2008;248(3):438-46.

5. Chari ST, Leibson CL, Rabe KG, Timmons LJ, Ransom J, de Andrade $M$, et al. Pancreatic cancer-associated diabetes mellitus: prevalence and temporal association with diagnosis of cancer. Gastroenterology. 2008;134(1):95-101.

6. Pannala R, Leirness JB, Bamlet WR, Basu A, Petersen GM, Chari ST. Prevalence and clinical profile of pancreatic cancer-associated diabetes mellitus. Gastroenterology. 2008;134(4):981-7.

7. Chu CK, Mazo AE, Sarmiento JM, Staley CA, Adsay NV, Umpierrez GE, et al. Impact of diabetes mellitus on perioperative outcomes after resection for pancreatic adenocarcinoma. J Am Coll Surg. 2010; 210(4):463-73.

8. Malleo G, Mazzarella F, Malpaga A, Marchegiani G, Salvia R, Bassi C, et al. Diabetes mellitus does not impact on clinically relevant pancreatic fistula after partial pancreatic resection for ductal adenocarcinoma. Surgery. 2013;153(5):641-50.

9. Chagpar RB, Martin RC, Ahmad SA, Kim HJ, Rupp C, Weber S, et al. Medically managed hypercholesterolemia and insulin-dependent diabetes mellitus preoperatively predicts poor survival after surgery for pancreatic cancer. J Gastrointest Surg. 2011;15(4):551-7.

10. Cannon RM, LeGrand R, Chagpar RB, Ahmad SA, McClaine R, Kim $\mathrm{HJ}$, et al. Multi-institutional analysis of pancreatic adenocarcinoma demonstrating the effect of diabetes status on survival after resection. HPB (Oxford). 2012;14(4):228-35.

11. El Nakeeb A, Salem A, Mahdy Y, El Dosoky M, Said R, Ellatif MA, et al 2016. Value of preoperative biliary drainage on postoperative outcome after pancreatico-duodenectomy: A case-control study. Asian J Surg. 2016; 9. pii: S1015-9584(16)30240-8.

12. El Nakeeb A, Atef E, El Hanafy E, Salem A, Askar W, Ezzat H, et al. Outcomes of pancreaticoduodenectomy in elderly patients. Hepatobiliary Pancreat Dis Int. 2016;15(4):419-27.

13. El Nakeeb A, Hamdy E, Sultan AM, Salah T, Askr W, Ezzat H, et al. Isolated Roux loop pancreaticojejunostomy versus pancreaticogastrostomy after pancreaticoduodenectomy: a prospective randomized study. HPB (Oxford). 2014;16(8):713-22.

14. American Diabetes Association. Standards of medical care in diabetes-2010. Diabetes Care. 2010;33 Suppl 1:S11-61.

15. Dindo D, Demartines N, Clavien PA. Classification of surgical complications: a new proposal with evaluation in a cohort of 6336 patients and results of a survey. Ann Surg. 2004;240(2):205-13.

16. Bassi C, Dervenis C, Butturini G, Fingerhut A, Yeo C, Izbicki J, et al. Postoperative pancreatic fistula: an international study group (ISGPF) definition. Surgery. 2005;138(1):8-13.

17. Koch M, Garden OJ, Padbury R, Rahbari NN, Adam R, Capussotti L, 
et al. Bile leakage after hepatobiliary and pancreatic surgery: a definition and grading of severity by the International Study Group of Liver Surgery. Surgery. 2011;149(5):680-8.

18. Wente MN, Bassi C, Dervenis C, Fingerhut A, Gouma DJ, Izbicki JR, et al. Delayed gastric emptying (DGE) after pancreatic surgery: a suggested definition by the International Study Group of Pancreatic Surgery (ISGPS). Surgery. 2007;142(5):761-8.

19. Ramos M, Khalpey Z, Lipsitz S, Steinberg J, Panizales MT, Zinner M, et al. Relationship of peri-operative hyperglycemia and postoperative infections in patients who undergo general and vascular surgery. Ann Surg. 2008:248(4):585-91.

20. Wright CD, Kucharczuk JC, O'Brien SM, Grab JD, Allen MS; Society of Thoracic Surgeons General Thoracic Surgery Database. Predictors of major morbidity and mortality after esophagectomy for esophageal cancer: a Society of Thoracic Surgeons General Thoracic Surgery Database risk adjustment model. J Thorac Cardiovasc Surg. 2009;137(3):587-95; discussion 596.

21. Little SA, Jarnagin WR, DeMatteo RP, Blumgart LH, Fong Y. Diabetes is associated with increased perioperative mortality but equivalent long-term outcome after hepatic resection for colorectal cancer. J Gastrointest Surg. 2002;6(1):88-94.

22. Ben Q1, Xu M, Ning X, Liu J, Hong S, Huang W, Zhang H, Li Z. Diabetes mellitus and risk of pancreatic cancer: a meta-analysis of cohort studies. Eur J Cancer. 2011;47(13):1928-37.

23. Huxley R, Ansary-Moghaddam A, Berrington de González A, Barzi F, Woodward M. Type-II diabetes and pancreatic cancer: a meta-analysis of 36 studies. Br J Cancer. 2005; 92(11):2076-83.
24. Pannala R, Leibson CL, Rabe KG, Timmons LJ, Ransom J, de Andrade $\mathrm{M}$, et al. Temporal association of changes in fasting blood glucose and body mass index with diagnosis of pancreatic cancer. Am J Gastroenterol. 2009;104(9):2318-25.

25. Chu CK1, Mazo AE, Sarmiento JM, Staley CA, Adsay NV, Umpierrez GE, Kooby DA. Impact of diabetes mellitus on perioperative outcomes after resection for pancreatic adenocarcinoma. J Am Coll Surg. 2010;210(4):463-73.

26. Malleo G, Mazzarella F, Malpaga A, Marchegiani G, Salvia R, Bassi C, et al. Diabetes mellitus does not impact on clinically relevant pancreatic fistula after partial pancreatic resection for ductal adenocarcinoma. Surgery. 2013; 153(5):641-50.

27. Nakata B, Ishikawa T, Amano R, Kimura K, Hirakawa K. Impact of preoperative diabetes mellitus on clinical outcome after pancreatectomy. Int J Surg. 2013;11(9):757-61.

28. Poon RT, Fan ST, Lo CM, Ng KK, Yuen WK, Yeung C, et al. External drainage of pancreatic duct with a stent to reduce leakage rate of pancreaticojejunostomy after pancreaticoduodenectomy: a prospective randomized trial. Ann Surg. 2007;246(3):425-33; discussion 433-5.

29. Mathur A, Pitt HA, Marine M, Saxena R, Schmidt CM, Howard TJ, et al. Fatty pancreas: a factor in postoperative pancreatic fistula. Ann Surg. 2007;246(6):1058-64.

30. Rosso E, Casnedi S, Pessaux P, Oussoultzoglou E, Panaro F, Mahfud $\mathrm{M}$, et al. The role of "fatty pancreas" and of BMI in the occurrence of pancreatic fistula after pancreaticoduodenectomy. J Gastrointest Surg. 2009;13(10):1845-51. 